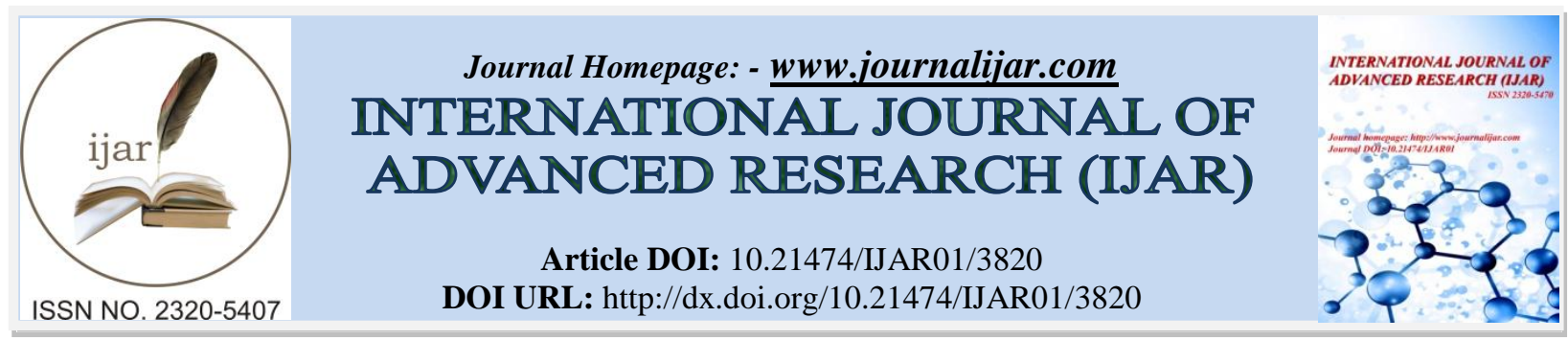

RESEARCH ARTICLE

\title{
EVALUATION OF BIOMEDICAL IMPORTANCE OF CHLOROGENIC ACID IN THE TREATMENT OF DIABETES MELLITUS IN IN-VIVO ALLOXAN INDUCED DIABETIC RAT MODELS.
}

\author{
Attiq Ur Rehman', "Wafa Majeed², Bilal Aslam², Muhammad Naeem Faisal' ${ }^{2}$, Asra Iftikhar ${ }^{2}$ and Aisha \\ Sultana ${ }^{2}$.
}

1. Punjab Medical College, Faisalabad, Pakistan.

2. Institute of Pharmacy, Physiology and Pharmacology, University of Agriculture, Faisalabad, Pakistan.

\section{Manuscript Info}

\section{Manuscript History}

Received: 09 February 2017

Final Accepted: 06 March 2017

Published: April 2017

Key words:-

Polyphenols, CGA, Biochemical, antihyperglycemic

\section{Abstract}

Objective: The present study is designed to investigate the role of Chlorogenic (CGA) acid in the regulation of glucose metabolism in alloxanized diabetic rat models.

Method: For the current study, 30 albino rats were divided into five groups. Diabetes was induced by a single intraperitoneal (i.p.) injection of alloxan monohydrate $(150 \mathrm{mg} / \mathrm{kg})$ in all groups except normal control group. Blood samples were collected at 0 and $28^{\text {th }}$ day of study. Hypoglycemic potential of chlorogenic acid (CGA) was determined.

Results: Results of biochemical parameters showed that level of serum glucose and glycosylated haemoglobin was significantly $(\mathrm{p}<0.05)$ decreased in CGA treated groups in dose dependent manner along with restored value of serum insulin. While level of serum glucose was observed to decrease significantly after the treatment of CGA. Concentration of serum LDL cholesterol, TC and TG was restored to normal range. While serum HDL cholesterol was raised that was comparable to normal control and glibenclamide treated group. Moreover, oxidative stress parameters and antioxidant profile have shown that CGA possessantihyperglycemic and hypolipidemic properties.

Conclusion: Dose dependent antidiabetic activity of CGA was observed.

Copy Right, IJAR, 2017,. All rights reserved.

\section{Introduction:-}

Intracellular glucose and lipid homeostasis is very dynamic for sustaining the elementary life events of a cell. Intracellular glucose and phospholipid metabolic syndromes are the origin of different types of metabolic disorders. These metabolic disorders are meticulouslylinked with the incidence and development of diabetes mellitus and obesity (Shengxiet al., 2013). Currently available therapeutic options for the treatment of diabetes mellitus are not only inadequate, but at the same time are also allied with undesirable side effects (Lincoffet al., 2007). Treatments with innovative mechanisms of action to contestmetabolic disorders would thus have noteworthy medical impacts.

Treatment of diabetes mellitus includes use of medications that decreaseglucose levels, together with insulin and oral hypoglycemic drugs. Mostmedications in existing use are utterly constrained by both theiradverse effects and high cost of therapy. Due to these contests,peoplehave resorted toinexpensive and readily available alternate sources,such as usage of medicinal plants and their phyto-constituents. The WHO approximates that $80 \%$ of the 
worlds' populations use plant based medicines for different ailments. Thesustained use of plant based medicinesis related to their cost effectiveness and minimal side effects (Moseset al., 2016).

Chlorogenic acid (CGA), one of the furthermostample polyphenol compounds in the diet of human beings, is a collection of phenolic metabolites formed by certain plants and avitalconstituent of coffee. It has been stated that coffee has the maximumconcentration of polyphenols (Olthof et al., 2001). Amassing evidence has confirmed that CGA shows many bioticpossessions, including antioxidant, anticarcinogenicand antibacterial activities, mainly hypoglycemic and lipid lowering effects (Bassoliet al., 2008). CGA has been newly claimed to control glucose and lipid metabolism (Zhanget al., 2011). Keeping in view the medicinal value of CGA, in the present investigation antihyperglycemic potential of chlorogenic acid has been explored in experimentally induced diabetic rat models.

\section{Material And Methods:-}

\section{Animals:-}

Thirty (30) healthy young albino rats weighing 180-200 g were used for study. Rats were kept at facility in animal room situated at Institute of Pharmacy, Physiology and Pharmacology. The animals were kept for two weeks as an acclimatization period prior to the start of experiment. They were housed 6/cage and received normal diet and water ad libitum.

\section{Chemicals and Drugs:-}

Alloxan monohydrate (AppliChem, Ottoweg-4, Germany) was used to induce experimental diabetes in rats. Tablet Glibenclamide (DAONIL, Sanofi-Aventis Pvt. Ltd) was administered orally at a dose of $10 \mathrm{mg} / \mathrm{kg}$ orally to the respective group. Chlorogenic acid was obtained from Sigma-Aldrich Company, St. Louis, USA.

\section{Induction of diabetes mellitus in experimental animals:-}

In overnight fasted rats, diabetes was induced by single i.p. injection of alloxan monohydrate $(150 \mathrm{mg} / \mathrm{kg}) 5 \% \mathrm{w} / \mathrm{v}$ in normal saline. Since, alloxan has capability of producing fatal hypoglycemia due to the enormous pancreatic release of insulin, so animals were given $20 \%$ glucose solution orally after 6 hrs. For next 24 hours, rats were fed 5\% glucose solution to prevent hypoglycemic shock. Diabetes was confirmed in rats by determining glucose level with glucometer after 72 hours of alloxan injection. Experimental rats having blood glucose level above $300 \mathrm{mg} / \mathrm{dl}$ were believed to be diabetic and included in further studies.

\section{Experimental Design:-}

The rats were divided in 5 groups with 6 rats in each group. After the induction of diabetes, rats received following treatments by intra gastric route. Group I: Normal control (Routine diet + water ad-libitum); Group II: untreated control (alloxan monohydrate, $150 \mathrm{mg} / \mathrm{kg}$ ); Group III: glibenclamide treated $(10 \mathrm{mg} / \mathrm{kg} / \mathrm{day})$; Group IV: treated group I (chlorogenic acid, $5 \mathrm{mg} / \mathrm{kg}$ ); Group V: treated group II (chlorogenic acid, $15 \mathrm{mg} / \mathrm{kg}$ ).

\section{Collection of blood samples:-}

Blood samples were collected at 0 and $28^{\text {th }}$ day. Collection was done in clot activator gel tubes. The serum was separated by centrifugation at $4000 \mathrm{rpm}$ for 10 minutes.

\section{Biochemical analysis:-}

Biochemical analysis for serum insulin (Abcam's ab200011- Insulin Human Simple step ELISA® kit) and serum glucose (Flutiest ${ }^{\circledR}$ GLU- Analyticon diagnostic kit) was performed. Lipid profile for serum triglycerides, serum total cholesterol (Dia Sys; Diagnostic Systems USA reagent kit method), serum HDL and serum LDL (Randox;Randox Laboratories LTD, UK, reagent kit method) was done. Total oxidative status, total antioxidant capacity, (Mohammed et al., 2009; Ohkawaet al., 1979) superoxide dismutase, serum malondialdehyde levels were calculated (Pandeyet al., 2011).

\section{Statistical analysis::-}

The results were expressed as mean \pm SE. Statistical analysis was conducted by ANOVA followed by Duncan's multiple range test (DMR) at $5 \%$ level of significance $(\mathrm{P} \leq 0.05)$. Statistical Package for Social Sciences (SPSS) version 3.16 was used for statistical analysis.

\section{Results:-}

On $28^{\text {th }}$ day level of serum glucose and glycosylated haemoglobin was significantly $(\mathrm{p}<0.05)$ raised in alloxan monohydrate treated group while serum insulin level was lowered in comparison to the normal control. While 
concentration of serum glucose and glycosylated haemoglobin was significantly decreased in CGA treated groups in dose dependent manner along with restored value of serum insulin that was comparable to the values of glibenclamide treated group (Table-1).

Table 1:- Effect of chlorogenic acid on serum glucose, serum insulin and glycosylated hemoglobin.

\begin{tabular}{|l|l|l|l|}
\hline Groups & Serum glucose $(\mathbf{m g} / \mathbf{d l})$ & Serum Insulin $(\boldsymbol{\mu I U} / \mathbf{m l})$ & $\begin{array}{l}\text { Glycosylated Hemoglobin } \\
(\% \text { age })\end{array}$ \\
\hline Control & $77.67 \pm 3.25 \mathrm{E}$ & $18.768 \pm 0.658 \mathrm{~A}$ & $5.72 \pm 0.12 \mathrm{~F}$ \\
\hline $\begin{array}{l}\text { Alloxan } \\
\text { monohydrate }\end{array}$ & $341.17 \pm 5.08 \mathrm{~A}$ & $6.283 \pm 0.817 \mathrm{E}$ & $13.92 \pm 0.70 \mathrm{~A}$ \\
\hline Glibenclamide & $92.83 \pm 2.94 \mathrm{DE}$ & $16.68 \pm 0.654 \mathrm{~B}$ & $6.05 \pm 0.45 \mathrm{EF}$ \\
\hline Treated I & $114.67 \pm 1.74 \mathrm{C}$ & $12.55 \pm 0.660 \mathrm{C}$ & $8.92 \pm 0.99 \mathrm{D}$ \\
\hline Treated II & $99.00 \pm 1.81 \mathrm{D}$ & $15.1 \pm 0.815 \mathrm{~B}$ & $6.62 \pm 0.27 \mathrm{EF}$ \\
\hline
\end{tabular}

Each value is expressed as mean \pm SE. Varying alphabet in each column shows significant statistical difference (p $<0.05)$

Figure-1 is graphical representation of blood glucose level in treated and untreated groups at $0,7^{\text {th }}, 14^{\text {th }}$ and $28^{\text {th }}$ day. After the administration of alloxan monohydrateat each weekly interval level of serum glucose was raised significantly $(\mathrm{p}<0.05)$ while level of serum glucose after the treatment of CGA was observed to decrease significantly by the end of $4^{\text {th }}$ week in both treated I and treated $\Pi$ groups dose dependently.

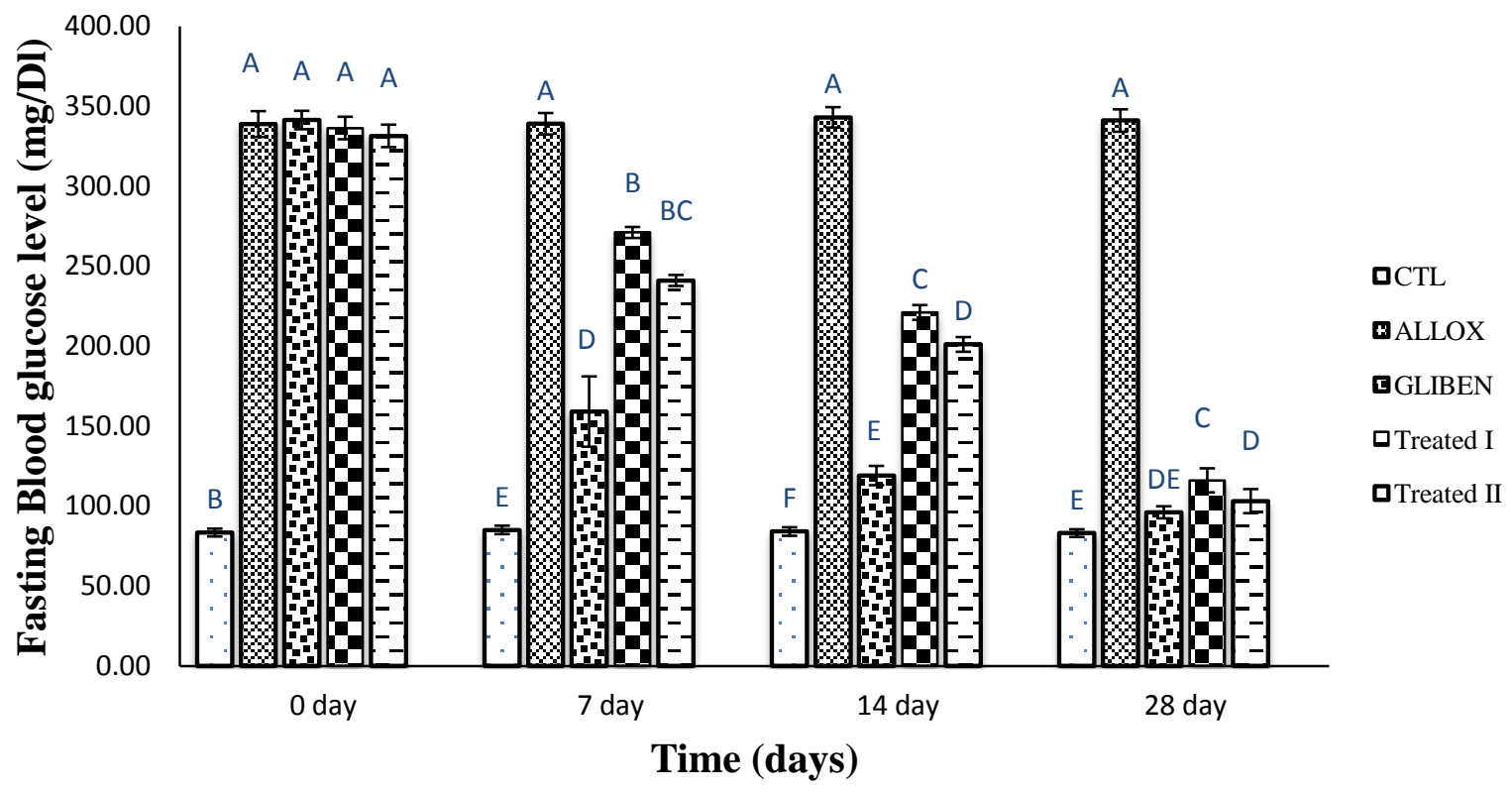

Fig \# 1:- Fasting Blood Glucose level after administration of glibenclamide and chlorogenic acid in alloxanized hyperglycemic rats.

Oxidative health markers:-

Experimental diabetic rats showed a significant elevation in serum TOS level, while treatment with chlorogenic acid showed decrease in the level of total oxidant status exhibiting lowering of oxidative stress (Figure-2) 


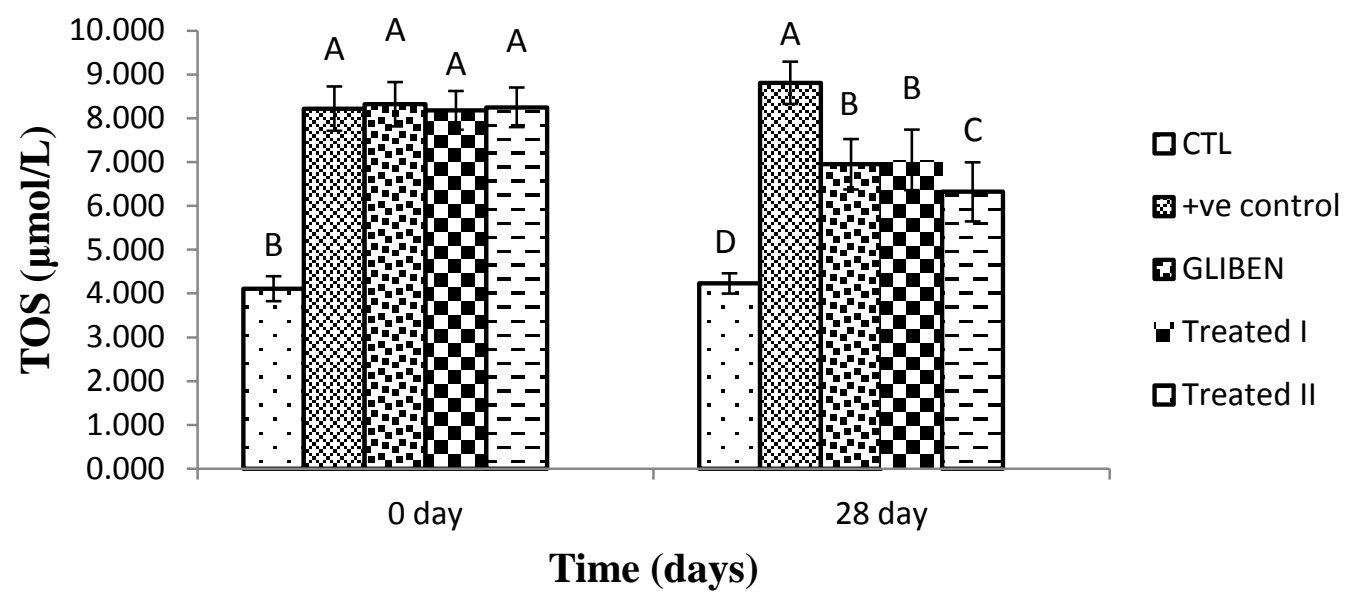

Fig \# 2:- Serum TOS level after administration of glibenclamide and chlorogenic acid.

Serum total antioxidant capacity (TAC) was decreased in alloxan treated rats due to over production of free radicals that increases oxidative stress markers. Whereas level of TAC in CGA and glibenclamide groups was significantly increased and that was comparable to normal control (Figure-3).

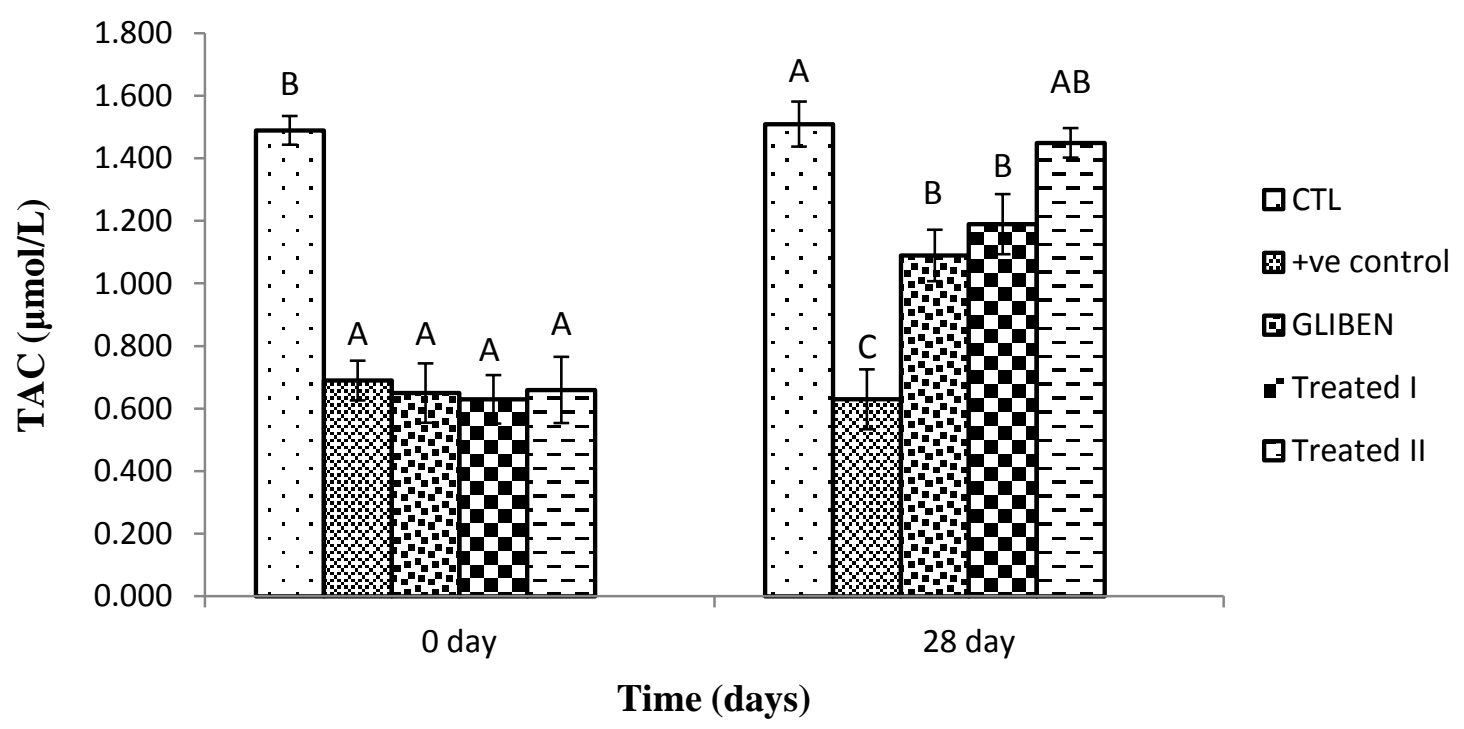

Fig.3:- Serum TAC level after administration of glibenclamide and chlorogenic acid

Experimental diabetic rats showed a significant decrease in serum SOD level, while treatment with chlorogenic acid and glibenclamide showed increase in the level of serum super oxide dismutase(Figure-4). 


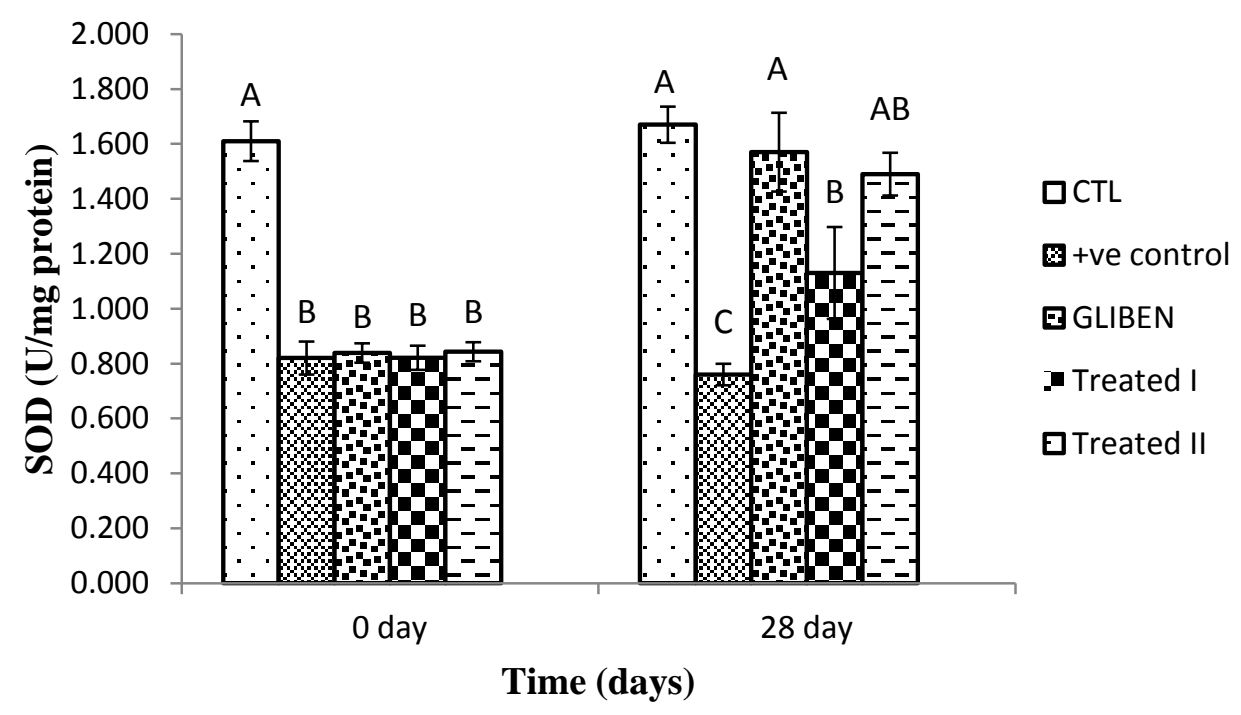

Fig. 4:- Serum SOD level after administration of glibenclamide and chlorogenic acid.

Serum MDA was increased in alloxan treated rats due to over production of free radicals that increases oxidative stress. Whereas level of MDA in CGA and glibenclamide groups was significantly decreased and that was comparable to normal control (Figure-5).

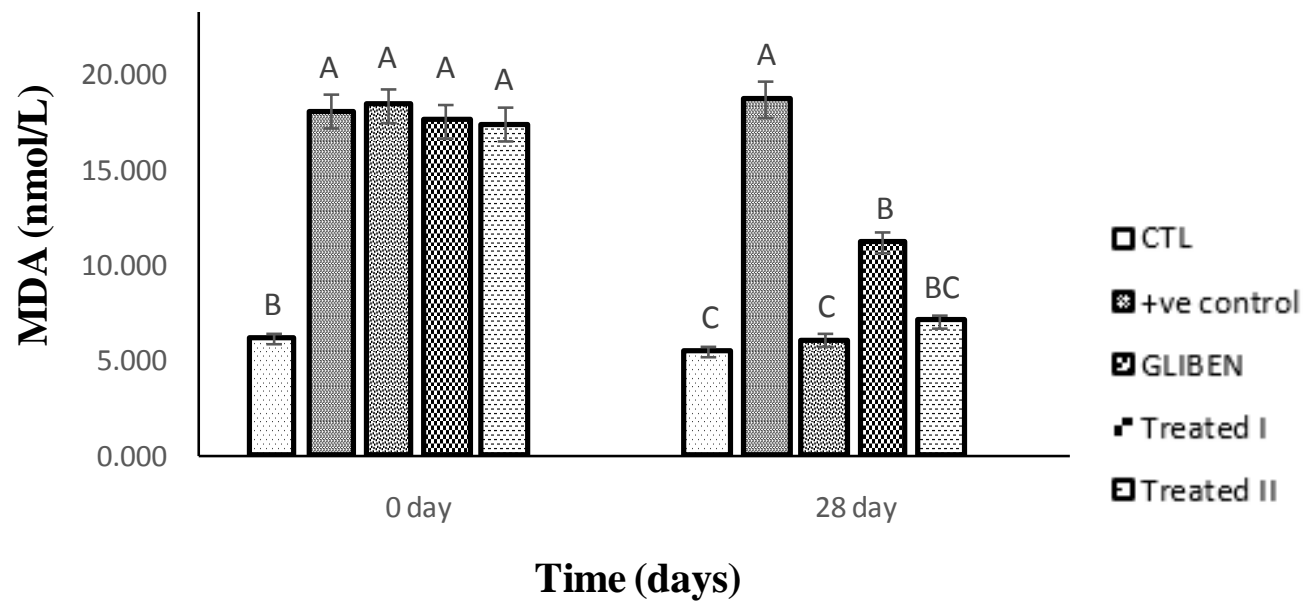

Fig.5:- Serum MDA level after administration of glibenclamide and chlorogenic acid.

When experimental rats were treated with alloxan monohydrate then concentration of total cholesterol (TC), triglycerides (TG) and low density lipoprotein (LDL) cholesterol was significantly elevated along with a significant decrease in level of high density lipoprotein (HDL) cholesterol. After treatment with CGA level of serum LDL cholesterol, TC and TG was restored to normal range. While concentration of HDL cholesterol was raised that was comparable to normal control and glibenclamide treated group (Table-2). 
Table 2:- Determination of lipid profile after treatment with chlorogenic acid

\begin{tabular}{|c|c|c|c|c|}
\hline Groups & $\begin{array}{ll}\begin{array}{l}\text { Total } \\
(\mathrm{mg} / \mathrm{dl})\end{array} & \text { Cholesterol } \\
\end{array}$ & Triglyceride (mg/dl) & $\begin{array}{l}\text { Serum } \\
(\mathbf{m g} / \mathbf{d l})\end{array} \quad$ HDL & $\begin{array}{l}\text { Serum } \\
(\mathrm{mg} / \mathrm{dl})\end{array}$ \\
\hline Control & $72.83 \pm 6.804 \mathrm{C}$ & $82.00 \pm 1.18 \mathrm{C}$ & $29.83 \pm 0.31 \mathrm{~A}$ & $11.58 \pm 0.45 \mathrm{C}$ \\
\hline $\begin{array}{l}\text { Alloxan } \\
\text { monohydrate }\end{array}$ & $108.67 \pm 3.471 \mathrm{~A}$ & $137.67 \pm 9.45 \mathrm{~A}$ & $16.33 \pm 0.33 \mathrm{C}$ & $28.25 \pm 0.92 \mathrm{~A}$ \\
\hline Glibenclamide & $74.45 \pm 4.945 \mathrm{C}$ & $89.00 \pm 3.76 \mathrm{C}$ & $27.00 \pm 0.86 \mathrm{~A}$ & $12.08 \pm 0.68 \mathrm{C}$ \\
\hline Treated I & $89.67 \pm 4.224 \mathrm{~B}$ & $107.33 \pm 3.57 \mathrm{~B}$ & $21.50 \pm 1.73 \mathrm{~B}$ & $16.92 \pm 0.78 \mathrm{~B}$ \\
\hline Treated II & $77.17 \pm 5.518 \mathrm{C}$ & $92.00 \pm 2.50 \mathrm{C}$ & $25.98 \pm 0.62 \mathrm{~A}$ & $14.02 \pm 0.69 \mathrm{C}$ \\
\hline
\end{tabular}

Each value is expressed as mean \pm SE. Varying alphabet in each column shows significant statistical difference (p $<0.05)$

\section{Discussion:-}

Diabetes mellitus is characterized by deficiency of insulin consequence in glucose intolerance and in aberrations of other metabolic fuels (Kolanuet al., 2017). It affects almost 3\% of population world widely. Awareness and information about the risk factors, complications and management of diabetes mellitus are important features for better control and improved quality of life (Wild et al., 2004). There are several restrictions for the use of oral hypoglycemics in the treatment of diabetes mellitus. As oral hypoglycemic agents are associated with severe side effects so focus is now diverted towards the use of natural origin based synthetic and semi-synthetic substances with more efficacy and less side effects for the treatment of diabetes mellitus. The trademark of both type 1 and 2 diabetes is the inability of the beta cell of pancreas to secrete the necessary amount of insulin to maintain the blood glucose homeostasis. The prediabetic state in type 2 diabetes mellitus is linked with the glucose intolerance and defective insulin homeostasis.

Alloxan monohydrate induced diabetes mellitus is a very useful investigational way of demonstrating the antihyperglycemic potential of newer agents. In the current study alloxan monohydrate (150 mg/kg b.w) was used to prepare diabetic models and serum glucose level was found to be meaningfully raised than in normal albino rats. Alloxan is a diabetogenic mediator which destroys $\beta$-cells of the islets of langerhans and causes increase in hyperglycemia (Bhaskaret al., 2016).

The mechanism involved in antihyperglycemic action of CGA might be the increased secretion of insulin from pancreatic beta cells. Previous data has revealed that CGA acts as insulin sensitizer and it works like metformin in increasing the insulin sensitivity on tissue site. At the same time CGA also reduces the phosphorylation of glucose by inhibiting the glucose-6-phosphatase activity. The hypoglycemic potential of CGA in alloxanized hyperglycemic rats was comparable to glibenclamide. Our findings are in agreement with previous research data (Ahrens and Thompson, 2013).

Our findings have demonstrated that after 28 days of treatment, chologenic acid ( $5 \mathrm{mg} / \mathrm{kg}$ and $15 \mathrm{mg} / \mathrm{kg}) \mathrm{showed}$ significant dose related antihyperglycemic activity in in-vivo diabetic models which was comparable to glibenclamide. Previous research data has revealed that the mechanism involved in antidiabetic activity of chlorogenic acid might be its potentiation effect on insulin action (Pariet al., 2010). Chlorogenic acid also enhances the glucose uptake by adipose tissues and muscles (Shengxiet al., 2013).

Chlorogenic acid is a hypoglycemic agent and also maintains the lipid homeostasis. Results of current study have demonstrated that chlorogenic acid significantly reduced the serum cholesterol and triglyceride levels in dose dependent manner. These results are in accordance with previous research studies (Wang et al., 2012).

The indicator of the oxidative stress is the total antioxidant capacity (TAC) (Young, 2001). TAC level was reduced considerably in group treated with alloxan in present study. TAC levels were markedly raised in rats treated with chlorogenic acid.Total oxidant status (TOS) acts as a determining factor of oxidative stress formed by reactive 
oxygen species. Excess amount of reactive oxygen species are produced in the pathological conditions which upsets the balance between oxidants and antioxidants (Harmaaet al., 2005). TOS level was increased markedly in alloxanized diabetic rats in the given study. However, TOS level was decreased by chlorogenic acid due to its ability to scavenger free radicals produced by alloxan. SOD display a cytoprotective effect (Lenzen, 2008). Our findings are related to increased level of SOD in chlorogenic acid treated rats.

In the given study, glycosylated haemoglobin level was markedly raised as compared to normal group, which is related to the high risk of retinopathy and renal complications. In contrast, administration of cholorogenic acid for 28 days, markedly reduced the level of glycosylated haemoglobin(Balamuruganet al., 2014). These results are in agreement with previous research studies.

\section{Conclusion:-}

Current study was perceived with an opinion to deliver scientific and pharmacological suggestions for antihyperglycemic potential of CGA. The results attained in present study may demonstrate valuable in discovering holistic approach for diabetes mellitus. However, further research studies are also required to elucidate the mechanisms involved in hypoglycemic potential of CGA as well as the comprehensive investigation for side effects of CGA is also required for its safe use in the treatment of diabetes mellitus.

\section{Declarations:-}

\section{Conflict of interest:-}

The authors declare that they have no competing interests.

\section{References:-}

1. Ahrens, M.J. and Thompson, D.L. (2013): Effect of Emulin on blood glucose in type 2 diabetics. J. Med. Food., 16(3): 211-215.

2. Balamurugan., Antony, N. andVeerabahu, R.M. (2014): Antidiabetic and antihyperlipidaemic activity of ethanol extract of Melastomamalabathricum Linn. leaf in alloxan induced diabetic rats. Asian. Pac. J. Trop. Biomed., 4: 442-448.

3. Bassoli, B.K.,Cassolla, P. andBorba-Murad G.R. (2008): Chlorogenic acid reduces the plasma glucose peak in the oral glucose tolerance test: effects on hepatic glucose release and glycaemia.Cell. Biochem. Function., 26(3): 320-328.

4. Bhaskar, S., Suresh, CJ., Nakuleshwar, DJ., Sunil, K.S. and Gaurav, S. (2016): Evaluation of anti-diabetic and heapatoprotectivity of Coriandrumsativumin alloxan induced experimental animals: a histopathology study. Int. J. Pharm. Sci. Res., 7(11): 4510-4515.

5. Harmaa, M.,Harmaa, M. and Erel, O. (2005): Measurement of the total antioxidant response in preeclampsia with a novel automated method. Eur. J. Obstet. Gynecol. Reprod. Biol.,118: 47-51.

6. Kolanu, B., Boddula, V. andVadakedath, S. (2017): Amino acid (Leucine) chromatography: A study of branched-chain aminoaciduria in type 2 diabetes. Cureus., 9(3): 1-8.

7. Lenzen, S. (2008): The mechanisms of alloxan- and streptozotocin-induced diabetes. J. Diabetologia. 51:216226.

8. Lincoff, A.M., Wolski, K., Nicholls, S.J. andNissen, S.E. (2007): Pioglitazone and risk of cardiovascular events in patients with type 2 diabetes mellitus: a meta-analysis of randomized trials. J. American. Med. Assoc., 298(10): 1180-1188.

9. Mohammed, A., Adelaiye, A.B., Bakari, A.G. andMabrouk, M.A. (2009): Anti-diabetic and some haematological effects of ethylacetate and n-butanol fractions of Ganodermalucidumaqueous extract in alloxan - induced diabetic wistar rats. Int. J. Med. Medic. Sci., 1(12): 530-535.

10. Moses, S.A., Peter, C.V. and Agnes, M.N. (2016): Hypoglycemic activity of aqueous root bark extract Zanthoxylumchalybeum in alloxan-induced diabetic rats. J. Diabetes. Res., 2016: 1-5.

11. Ohkawa, H., Ohushi, N. and Yagi, K. (1979): Assay for lipid peroxidation in animal tissue by thiobarbituric acid reaction. J. Annal. Biochem., 95: 351-358.

12. Olthof, M.R., Hollman, P.C.H. and Katan, M.B. (2001): Chlorogenic acid and caffeic acid are absorbed in humans. J. Nutrition., 131(1): 66-71.

13. Pandey, A., Tripathi, P., Pandey, R., Srivatava, R. andGoswami, S. (2011): Alternative therapies useful in the management of diabetes: A systematic review. J. Pharm. Bioallied. Sci., 3(4): 504-512. 
14. Pari, L., Karthikesan, K. and Menon, V.P. (2010): Comparative and combined effect of chlorogenic acid and tetrahydrocurcumin on antioxidant disparities in chemical induced experimental diabetes. Mol. Cellular.Biochem., 341(2): 109-117.

15. Shengxi, M., Jianmei, C., Qin, F., Jinghua, P. and Yiyang, H. (2013): Roles of chlorogenic acid on regulating glucose and lipids metabolism: A review. Evidence. Based. Comp. Alter. Med.,2013: 1-11.

16. Wang, J.H., Liu, Y.L. and Li, C.L. (2012): Effect of chlorogenic acid extracted from Eucommiaulmoides on hyperlipemic mice induced by high fat diet. Sci. Technol. Food. Industry., 15: 360-362.

17. Wild, S., Roglic, G. and Green, A.(2004): Global prevalence of diabetes: estimates for the year 2000 and projections for 2030. Diabetes. Care., 27:1047-53.

18. Young, I.S. (2001): Measurement of total antioxidant capacity. J. Clinic. Pathol. 54: 339.

19. Zhang, L.T., Chang, C.Q., Liu, Y. and Chen, Z.M. (2011): Effect of chlorogenic acid on disordered glucose and lipid metabolism in db/db mice and its mechanism.Acta. Academiae. Medicinae. Sinicae., 33(3): 281-286. 